\title{
IMPACTOS DA PANDEMIA DE COVID-19 NAS PRÁTICAS DE AVALIAÇÃO DA APRENDIZAGEM NA GRADUAÇÃO
}

\author{
IMPACTS OF THE COVID-19 PANDEMIC ON UNDERGRADUATE \\ LEARNING ASSESSMENT PRACTICES
}

\author{
Joe Garcia \\ Doutor em Educação pela PUCSP \\ Professor Adjunto da Universidade Tuiuti do Paraná (UTP) \\ prof_joegarcia@yahoo.com \\ (D) Nicolas Fish Garcia \\ Mestrando em Música (UFPR) \\ Professor da International School of Curitiba (ISC) \\ nicolasfsgarcia@gmail.com
}

\begin{abstract}
Resumo: Este artigo apresenta um estudo sobre o impacto da pandemia de COVID-19, ocorrida no primeiro semestre de 2020, sobre a avaliação da aprendizagem de estudantes de graduação. Questionamos um conjunto de professores, de diferentes universidades brasileiras, sobre mudanças nas suas práticas de avaliação, introduzidas no contexto do ensino remoto e das adaptações pedagógicas necessárias frente à pandemia. A pesquisa, de natureza qualitativa e exploratória, foi realizada por meio de entrevistas realizadas on-line. Os dados obtidos foram submetidos a uma abordagem de análise de conteúdo e interpretação teórica. A pesquisa identificou mudanças nas estratégias didáticas, nos critérios avaliativos e nos significados das práticas de avaliação.
\end{abstract}

Palavras-chave: Educação superior. Avaliação. Aprendizagem. Pandemia. COVID-19.

Abstract: This article presents a study on the impact of the COVID-19 pandemic, which occurred in the first semester of 2020, on the assessment of undergraduate students' learning. We questioned a group of professors, from different Brazilian universities, about changes in their assessment practices, introduced in the context of remote education and the necessary pedagogical adaptations in the face of the pandemic. The research, of a qualitative and exploratory nature, was carried out through interviews conducted online. The data obtained were submitted to a content analysis approach and theoretical interpretation. The research identified changes in teaching strategies, in the evaluation criteria and in the meanings of the evaluation practices.

Keywords: Higher education. Assessment. Learning. Pandemia. COVID-19.

\section{Para citar - (ABNT NBR 6023:2018)}

GARCIA, Joe; GARCIA, Nicolas Fish. Impactos da pandemia de COVID-19 nas práticas de avaliação da aprendizagem na graduação. Eccos - Revista Cientifica, São Paulo, n. 55, p. 1-14, e18870, out./dez. 2020. Disponível em: https://doi.org/10.5585/eccos.n55.18870. 


\section{Introdução}

Ao longo da história contemporânea as universidades têm estado conectadas a transformações e crises importantes que afetaram o planeta. Tal como observou Kerr (1990), a educação superior não consegue escapar da história. No século passado, por exemplo, as duas grandes guerras mundiais afetaram em vários aspectos o funcionamento de muitas das principais universidades na Europa e de outros continentes (CARDOZIER, 1993; DARIANSMITH e WAGHORNE, 2019, RUDY, 1991; TAYLOR, 2018). Argumentamos neste artigo que o devir das universidades segue igualmente entrelaçado à história. A universidade, como bem escreve Marilena Chaui (2001, p. 35), "realiza e exprime de modo determinado a sociedade de que é e faz parte", ela é "uma expressão historicamente determinada de uma sociedade determinada".

No primeiro semestre de 2020 a história social do planeta foi abalada com o surto de um novo coronavírus, que elevado à condição de pandemia desencadeou medidas de isolamento social que afetaram a educação em ao menos 200 países (UNESCO, 2020). Este foi também o caso do Brasil, onde escolas e universidades foram fechadas, as aulas presenciais suspensas e muitas dessas instituições passaram a adotar o que se pode denominar de práticas emergenciais de educação (HODGES et al., 2020). Dentro deste cenário, este artigo dedica atenção ao quadro de mudanças pedagógicas observadas no ensino universitário, destacando a questão da avaliação. A transição abrupta para práticas emergenciais de ensino remoto impactou o currículo, pois envolveu decisões e adaptações em seus elementos, tais como as práticas de avaliação da aprendizagem, uma das dimensões fundamentais do trabalho dos professores. É esse o contexto da investigação aqui apresentada, cujo objetivo é analisar a perspectiva de um grupo de professores universitários sobre as transformações nas práticas de avaliação da aprendizagem na graduação, no contexto de adaptação pedagógica frente à pandemia do novo coronavírus.

Na primeira parte do texto, examinamos o surgimento da pandemia de coronavírus e seus impactos no funcionamento das universidades, destacando questões envolvendo transformações na avaliação. $\mathrm{Na}$ segunda parte, descrevemos o levantamento de dados realizado e analisamos os dados obtidos por entrevistas, junto a um grupo de professores de graduação de diferentes áreas do conhecimento, refletindo sobre as mudanças apontadas em suas práticas de avaliação da aprendizagem. E na seção de considerações finais do artigo sintetizamos algumas percepções e análises teóricas elaboradas ao longo da pesquisa. 


\section{Pandemia e o cenário da educação superior}

Em fevereiro de 2020, no início do ano letivo das universidades brasileiras, a mídia noticiava, com grande destaque, a progressão da disseminação de um novo coronavírus, em diversos países, sobretudo na Ásia e na Europa. Esse vírus havia sido identificado no final de dezembro de 2019, na cidade de Wuhan, na China, que se tornou o primeiro epicentro da nova crise de saúde pública internacional. No Brasil, no final daquele mês, o Ministério da Saúde confirmou o primeiro caso do novo coronavírus, na cidade de São Paulo. Tratava-se de um homem que havia retornado de uma viagem à Itália, da região da Lombardia, a mais fortemente afetada pela doença naquele país (CRODA et al., 2020). Esse caso estabeleceu um marco inicial da contaminação no território brasileiro, que em poucas semanas iria requer medidas de isolamento social, com implicações ao funcionamento das instituições de educação superior, bem como de escolas de todos os segmentos da educação básica.

No início de março, as universidades ainda seguiam funcionando em ritmo de normalidade, com aulas e atividades presenciais, mas sob um clima de incerteza com relação ao desdobramento do semestre letivo. Em 11 de março, a Organização Mundial da Saúde (OMS) declarou oficialmente a existência de uma pandemia de coronavírus. Em todos os Estados do Brasil houve a suspensão de aulas presenciais, em escolas e universidades, como parte das estratégias de isolamento social para desacelerar o avanço da pandemia do novo coronavírus. Essa mesma medida também foi adotada em mais de 190 países, afetando a rotina de mais de 1,5 bilhão de crianças e jovens, mais de $90 \%$ dos estudantes no mundo (UNESCO, 2020).

O fechamento das instituições educacionais, que atendeu medidas emergenciais de isolamento social, seguindo protocolos internacionais de segurança, trouxe inevitáveis e importantes modificações na rotina pedagógica dominante das universidades. No entanto, a educação não foi interrompida em boa parte das universidades brasileiras, particularmente nas instituições privadas, que concentram a maior parcela de estudantes da educação superior. Segundo o último Censo da Educação Superior, dos cerca de 8,5 milhões de estudantes universitários no país, 6,4 milhões estão matriculados em cursos presenciais. Isso significa que a pandemia afetou a rotina de aulas presenciais de aproximadamente $75 \%$ dos estudantes universitários brasileiros (BRASIL, 2019).

Embora não tenha sido a totalidade das universidades brasileiras a migrar para práticas de ensino remoto, uma parte significativa delas passou a funcionar no mundo digital para seguir o cumprimento do calendário acadêmico. Esse ajuste trouxe diversas implicações, 
particularmente por ter sido realizado em um tempo muito curto - uns poucos dias em algumas instituições e algumas semanas em outras. As mudanças inevitavelmente afetaram o trabalho pedagógico dos professores, que se adaptaram à urgência do momento, mesmo sem o devido tempo para formação, planejamento e elaboração de materiais para serem utilizados em suas disciplinas, que passaram ao regime de ensino remoto.

Um Parecer do Conselho Nacional de Educação (BRASIL, 2020), aprovado no final de abril, sugeriu a continuidade das atividades síncronas e assíncronas de ensino e aprendizagem nas universidades, com adaptações para prover aulas não presenciais. Afirmando o exercício de autonomia e responsabilidade dessas instituições, na condução de seus projetos acadêmicos, recomenda que estas definam a realização das avaliações de forma remota, bem como a "realização de testes on-line ou por meio de material impresso entregues ao final do período de suspensão das aulas". Recomenda a substituição de atividades presenciais relacionadas à avaliação, por outras mediadas por tecnologias digitais de informação e comunicação, adequadas à infra-estrutura e interação necessárias.

Apesar do conhecimento acumulado há décadas sobre educação digital, bem como das orientações governamentais, as circunstâncias dessas mudanças, notadamente acima do controle das instituições, impuseram adaptações e até mesmo alguma provisoriedade nas práticas docentes, que poderiam ser mais apropriadamente denominadas de ensino remoto emergencial do que educação on-line (HODGES et al., 2020). Um programa de educação online deve sustentar a aprendizagem dos estudantes com infraestrutura, um currículo apropriado e ambiente de interação social. É fundamental dispor de recursos digitais tais como plataformas, bibliotecas e materiais de orientação e estudo. Em contraste o ensino remoto emergencial tende a apresentar práticas de avaliação da aprendizagem que são usualmente adaptações daquelas exercidas no ensino presencial (HODGES et al., 2020). De todo modo, mesmo essa abordagem emergencial e provisória de educação impõe transformações ou adaptações nas práticas de ensino que impactam seus elementos didáticos, tais como a avaliação. E sendo essa uma dimensão fundamental do trabalho docente, suas configurações, adaptações ou improvisações devem ser investigadas - sendo justamente essa a proposição deste artigo.

Segundo Means, Bakia e Murphy (2014), a avaliação da aprendizagem no contexto da educação on-line apresenta algumas distinções ou princípios que lhes são próprias. Nesse caso, a avaliação deve sinalizar se o aluno está pronto para o novo conteúdo, bem como fornecer a ele feedback sobre seu estado de aprendizagem e identificar quando está em risco de fracasso. Além disso, deve fornecer informações sobre como adaptar e sustentar as aprendizagens dos estudantes. Não se trata, assim, de simplesmente aplicar um instrumento de medição da 
aprendizagem e lançar uma nota no sistema. Há, portanto, detalhes a considerar, sobretudo envolvendo a distinção entre práticas de avaliação e de verificação da aprendizagem (LUCKESI, 2011).

Para uma efetiva educação on-line é necessário um ecossistema digital que englobe professores, estudantes e conhecimento (BRISCOE, SADEDIN e DE WILDE, 2011). Esse conceito refere-se a um novo paradigma na interação entre seres humanos e tecnologias digitais. Nele, professores e alunos interagem com tecnologias e serviços, bem como com contextos sociais e culturais, que exercem um papel de ambiente ampliado na sustentação dos processos de ensino e aprendizagem (LAANPERE et al., 2012). Não se trata, assim, de uma mudança simples, baseada na adoção de ferramentas digitais. Trata-se de um avanço complexo, que exige investimento em infraestrutura, formação de professores e mudança cultural na escola - e tudo isso leva tempo. No entanto, a conjugação desses elementos envolve um tempo em conflito com a velocidade de mudança imposta pela pandemia.

\section{Mudanças nas práticas de avaliação da aprendizagem}

Investigar a avaliação sempre requer uma reflexão ampla e atenta ao pensamento dos professores, pois envolve bem mais que apenas considerar quais instrumentos eles utilizam em suas práticas pedagógicas. Tal como sugere Dias Sobrinho (2008), a avaliação precisa ser pensada como uma prática social, intersubjetiva e relacional, que envolve uma produção de sentidos sobre como se cumpre a formação dos estudantes, quais os princípios e valores que estão sendo contemplados em sua educação. Segundo Eisner (1991), a pesquisa em educação tem um papel a exercer, particularmente de orientar ações em um contexto de mudança. É o que desejamos realizar pela análise do ensino universitário em meio ao cenário de pandemia, suas transformações e seus significados, procurando compreender como efetivamente os professores pensam e atuam, diante de um desafio de mudança, de adaptação ao novo. Esse papel é certamente complexo, pois envolve escolhas delicadas sobre como o pesquisador deve proceder. Neste caso, decidimos por uma pesquisa qualitativa e exploratória, apoiada em um processo de amostragem intencional (PATTON, 1991), tendo por referência a intensidade da experiência dos participantes selecionados em relação ao tema investigado.

O levantamento de dados desta pesquisa envolveu entrevistas on-line, com perguntas abertas, junto a um grupo de professores universitários, tendo por foco suas práticas de avaliação da aprendizagem, no contexto do ensino remoto emergencial. Esse procedimento metodológico seguiu protocolos éticos estabelecidos para a pesquisa científica em Ciências 
Humanas. Por meio desse levantamento foram obtidos dados exploratórios sobre adaptações, mudanças e ressignificações nas práticas de avaliação. Ao total, registramos os relatos de 17 professores universitários, que atuavam em 12 diferentes instituições de educação superior no Brasil, ensinando em 5 áreas distintas: ciências humanas; ciências biológicas; ciências da saúde; ciências exatas; letras e artes. Para as três primeiras áreas listadas acima, entrevistamos 3 professores, e apenas 2 para as restantes. Para compor esse grupo de professores utilizamos critérios de amostragem intencional por intensidade, tal como proposto por Patton (1991). Selecionamos participantes com experiências mais significativas envolvendo particularmente mudanças nas práticas de avaliação, no período de ensino remoto desencadeado pela pandemia mundial do novo coronavírus. A finalidade central das perguntas apresentadas aos professores foi identificar possíveis alterações e significações introduzidas na aprendizagem.

Em linhas gerais, todos os professores sinalizaram ter feito algum tipo de ajuste ou mudança nas suas práticas (até então) usuais de avaliação, seja envolvendo forma ou significado. No entanto, os elementos descritivos mencionados por eles, para se referir às mudanças efetuadas, mostraram-se bastante plurais - um reflexo provável das distinções epistemológicas, bem como pedagógicas, entre as suas áreas de conhecimento, bem como diferenças no próprio entendimento didático, entre eles, sobre a função da avaliação da aprendizagem naquele nível de ensino.

Diante da complexidade dos relatos obtidos nas entrevistas, recorremos a um modo de análise do conteúdo, de natureza qualitativa, proposta por Bardin (1977). Com esse procedimento pudemos distinguir categorias semânticas latentes nos relatos dos professores, que tornaram possível uma compreensão interpretativa ampliada sobre suas perspectivas. Tais categorias refletem mudanças de forma e significado nas práticas de avaliação. Elas se referem a mudanças nas estratégias didáticas, nos critérios avaliativos e nos significados da avaliação. A seguir apresentamos e exploramos cada uma dessas perspectivas de leitura encontradas no conteúdo das entrevistas.

\section{a. Mudanças nas Estratégias Didáticas}

A primeira categoria identificada pela análise do conteúdo das entrevistas refere-se a mudanças nas estratégias didáticas da avaliação. Entre os professores, verificou-se um conjunto de alterações (em maior ou menor grau) nos procedimentos de avaliação usualmente utilizados por eles no contexto presencial. Alguns deles relataram, por exemplo, terem solicitado trabalhos escritos, individuais ou em grupo, ao invés de aplicar provas escritas - uma alternativa usual no contexto de ensino presencial nas universidades. Outros informaram ter aplicado provas, de modo similar ao usual, mas com ajustes, em função do ensino remoto. Tais 
mudanças incluem adaptações, simplificações, trocas e substituições de procedimentos, bem como a adoção de um número menor de dispositivos de avaliação - comparado à variedade de práticas até então utilizadas nas disciplinas ministradas no ensino presencial.

Os procedimentos descritos como tendo sido introduzidos nas práticas de avaliação exercidas por alguns professores, no contexto de ensino remoto, incluem: autoavaliação, provas abertas, questionários e tarefas compartilhadas, bem como avaliação baseada na intensidade de participação nas atividades durante as aulas remotas, tais como apresentações, explicações, debates, etc. É importante destacar que tais abordagens, cuja utilização pode ser encontrada no ensino presencial, foram introduzidas por uma parcela dos professores entrevistados devido às condições do ensino remoto emergencial, incluindo a necessidade de usar tecnologias digitais, ao grau de adaptação a elas e ao comportamento dos alunos, entre outros fatores - alguns deles bastante subjetivos, como a "segurança" no domínio de plataformas online.

Esse deslocamento de práticas habituais, ainda que possa parecer algo simples, expressa significados pedagógicos a considerar. Hadji (1997) nos lembra que o ato de avaliar precisa considerar as circunstâncias, o contexto, e não somente os instrumentos a utilizar. Há uma relação entre as circunstâncias da avaliação e as informações que seus dispositivos recolhem. Deixar de considerar o contexto em que estamos avaliando os alunos, pode nos distanciar e verdadeiramente alienar do que desejamos saber sobre eles. Tal como escreve Luz (1997, p. 62), mesmo que uma determinada técnica de avaliação seja correta, ainda deve ser apropriada ao momento e objetivo proposto. Diferentes circunstâncias pedagógicas podem exigir a utilização de abordagens distintas de avaliação. Tal era o cenário em que se encontravam os professores universitários, durante o período de pandemia, no primeiro semestre de 2020.

A análise revelou que as escolhas dos professores procuravam integrar tanto as demandas curriculares quanto a perspectiva da experiência dos alunos. De um lado, a avaliação precisa estar a serviço de uma agenda pedagógica, sendo fundamental que procure distinguir conhecimentos, habilidades e atitudes consideradas importantes. Com isso, suas práticas sempre revelam valores, interesses, aspirações e ideologias (ROMÃO, 2005). Tal como observa Philippe Meirieu, a avaliação sempre tem em mente alguma competência que os estudantes supostamente devem dominar (MEIRIEU, 2002, 2005). Por outro lado, a avaliação também precisa ser uma ação pedagógica, na qual os professores acolhem a situação em que se encontram os estudantes (LUCKESI, 2005). Um dos professores entrevistados informou que mudou a avaliação, sem deixar de lado os objetivos gerais de aprendizagem, mas "evitando métodos que pudessem colocar os estudantes em risco ou sobrecarregados". 
Segundo Hadji (1992), o ato de avaliar envolve pronunciar-se sobre uma realidade, em um determinado contexto. $\mathrm{O}$ modo como os professores escolhem avaliar deve estar embasado em um contexto pedagógico. Ao mesmo tempo, essa ação revela as circunstâncias próprias como os estudantes vivem a experiência educacional. Assim, a avaliação nem sempre revela o que os professores desejam ver, mas ela certamente mostra algo a eles. Em alguns casos, o que pode se tornar mais visível é a angústia dos estudantes. Quando utilizamos um instrumento de avaliação com perguntas, por exemplo, desejamos ter acesso não somente às respostas dos alunos, o que eles pensam, mas como eles estão vivendo o contexto da própria educação. Escolhemos um modo de avaliar em função do que desejamos ver. Mas, aquilo que os professores desejam ver quando avaliam pode ser muito variável em função das circunstâncias em que realizam o ensino.

As mudanças relatadas pelos professores se revelaram tão plurais tanto quanto suas racionalidades. Elas expressam compromissos pedagógicos, que incorporam considerações éticas. Suas decisões procuram conjugar as demandas do currículo com as condições concretas dos alunos - tais como o acesso a materiais e domínio de tecnologias. Parece claro que expectativas aparentemente simples sobre a elaboração de trabalhos, por exemplo, podem resultar em desigualdade de desempenho entre os alunos, ameaçando as necessárias condições de equidade. A nova normalidade pedagógica estabelecida pela pandemia parece fornecer motivos para os professores colocarem em perspectiva seus modos de avaliação, voltando a olhar com interrogação suas ações, seus motivos, suas expectativas.

b. Mudança nos Critérios da Avaliação

Dentre os professores entrevistados, todos afirmaram ter efetuado alguma mudança, voluntária ou involuntária, em suas práticas de avaliação. A análise do conteúdo dos seus depoimentos indica que mais de metade deles menciona ter alterado algum elemento ou detalhe dos seus critérios de avaliação. O que isso significa? Segundo Hadji (2001), os critérios de avaliação usados pelos professores são construídos com base em expectativas. Estas podem ter muitas origens, tais como as políticas educacionais, as diretrizes ou projetos institucionais, bem como o olhar dos próprios professores, cuja autoridade usualmente se mostra muito presente nas decisões sobre como os estudantes devem ser avaliados. Esse sistema de expectativas produz um entendimento usado pelos professores sobre qual deve ser o estado de relação dos estudantes com o conhecimento. A avaliação, assim, "é uma operação de leitura da realidade", baseada em expectativas (HADJI, 2001).

Os professores constroem expectativas sobre o desempenho dos estudantes tomando por base visões idealizadas sobre estes. Suas expectativas expressam o que eles desejam ver ou suas 
crenças sobre qual deve ser o desempenho dos estudantes. Expectativas têm a função de guiar comportamentos (ROESE e SHERMAN, 1997), assim fornecem uma direção e modo como olhamos as pessoas. Nesse sentido, mudanças de expectativa entre professores podem refletir alterações em suas visões, valores e crenças, com relação ao desempenho dos alunos e sobre como devem realizar a tarefa de avaliar.

Utilizar provas, trabalhos escritos ou apresentações orais, por exemplo, são alternativas que, mesmo mantidas em seu formato original, pode ter recebido uma leitura avaliativa segundo critérios agora distintos. As razões para essa mudança, encontradas entre os professores entrevistados, são plurais. No entanto, puderam ser agrupadas em duas categorias gerais de significado. Uma delas explica a mudança pela leitura pedagógica e humana da situação geral dos alunos, no contexto da pandemia. A outra se refere a diretrizes ou valores coletivos ou institucionais.

Alguns professores entrevistados sugeriram que manter os mesmos critérios faria perder um pouco a percepção sobre alguns detalhes da aprendizagem. Os critérios usuais, no contexto de ensino remoto emergencial, poderiam introduzir alguma incerteza em desfavor dos alunos. Mudar, no entanto, foi algo entendido como necessário e significativo, pois os professores entendiam que deveriam considerar o estresse, bem como as condições emocionais dos estudantes, por exemplo, pois são aspectos psicológicos relacionados à aprendizagem (STEPHAN, M.; MARKUS, S.; GLÄSER-ZIKUDA, 2019). Ao mesmo tempo, algumas mudanças foram motivadas, ou estabelecidas, em função de diretrizes institucionais ou por juízos elaborados dentro dos coletivos de professores. Mas, não apenas em universidades brasileiras houve mudanças nas políticas institucionais sobre avaliação. Nos Estados Unidos, instituições emblemáticas como a Harvard University, anunciaram mudanças em seus critérios (LINCOLN, 2020). A avaliação da aprendizagem faz sentido no contexto de um projeto pedagógico institucional e de um projeto de ensino (LUCKESI, 2011), e quando estes são alterados, aquela segue na mesma direção.

Esta segunda categoria, destacada pela análise de conteúdo das entrevistas, revela uma dimensão importante nas mudanças que os professores introduziram em suas práticas pedagógicas relacionadas à avaliação. Ela aponta uma redefinição de valores, talvez pequena e impermanente, mas ainda assim um evento significativo no cenário da educação superior, que pode se tornar um marco para mudanças mais elaboradas no futuro.

\section{c. Mudança de Significado}

Segundo uma parte dos professores entrevistados, o período de pandemia, as medidas de isolamento social e a transição para o ensino remoto, solicitaram ajustes em suas práticas 
docentes, mas não sem reflexão sobre o próprio significado do ato pedagógico. O contexto requereu ensinar em condições diferentes os mesmos conteúdos do currículo. E isso implicou também alterações de significados, pois não estavam ensinando com expectativas idênticas àquelas praticadas até o semestre acadêmico anterior. As mudanças de significado nas práticas de ensino, articuladas a diferentes expectativas de aprendizagem, implicaram ajustes nos critérios e interpretação das práticas avaliativas. Essa aprendizagem deveria ter "espaço" para se apresentar diferente, sob o impacto das circunstâncias. Com isso, mudou algo nas expectativas e intencionalidade da avaliação. A pandemia não interrompeu a obrigatoriedade da avaliação nas universidades, que se manteve fundamental. Mas, para aqueles professores, esta passou a ser exercida sob alguns significados diferentes.

Quando os professores planejam a avaliação, precisam considerar os significados das suas escolhas segundo suas propostas de ensino, bem como do projeto da instituição onde atuam. Além disso, ela envolve uma construção que deve conjugar uma perspectiva pedagógica, que compreende uma dimensão ética, com uma leitura sobre aspectos relevantes do contexto em que ocorre (TITTLE, HECHT e MOORE, 2005), o que engloba a situação dos estudantes. Ela é uma prática didática que precisa estar baseada em critérios que fazem sentido em um contexto mais amplo do que a sala de aula. A avaliação, bem sabem os professores, é um modo de atribuir significado ao desempenho dos estudantes e isto possui consequências sociais (MESSICK, 1989). Quando os professores expressam que houve mudança de significado na avaliação, estão se referindo a possíveis elementos de um conjunto de aspectos significativos relacionados aos indivíduos e ao contexto específico em que atuam.

A principal diferença nas práticas de avaliação, envolvendo mudança de significado, refere-se a direcionar o seu foco para distinguir e valorizar o que se poderia denominar de “aprendizagens relevantes". Nessa perspectiva, que pode envolver diferentes estratégias de avaliação, os professores recorrem a práticas que devem tornar possível aos alunos mostrar o domínio de aprendizagens significativas, mais do que a capacidade de reproduzir quantidades de conteúdos. Isso, no entanto, leva à reflexão sobre o papel essencial dos critérios sobre quais sejam as aprendizagens mais relevantes. Estas podem ser definidas pelos professores, como usualmente ocorre, mas também surgir de ideias e propostas dos estudantes. É também importante que haja clareza e compreensão adequada sobre tais critérios, tanto entre professores, quanto entre os estudantes.

Avaliar segundo essa perspectiva de significado ajuda os professores não somente a tornar visível o que os estudantes sabem, mas também suas visões e modos de entendimento sobre o que seria particularmente relevante, para eles, do conjunto de conteúdos que são 
estudados. Em um dos depoimentos, uma professora assim expressa: "Mudei minha expectativa e não o método da avaliação", e destaca: "Os estudantes precisam mostrar aprendizagem relevante". Em outro depoimento, encontramos a ideia que houve "mudança de foco" da avaliação, que se deslocou da "capacidade de reproduzir quantidades de conteúdos”, para a "compreensão do que seja mais relevante entre os conteúdos".

Certamente esta perspectiva interpretativa, que destacamos da visão dos professores entrevistados, não pode ser tomada como uma espécie de princípio universal para orientar as práticas avaliativas na graduação. No entanto, essa ideia, em linhas gerais, sinaliza um modo possível de engajamento dos estudantes nos processos avaliativos, algo desejável, embora nem sempre observado na educação superior. Esse modo de participação se conecta ao que Mezirow (1991) denominou de "avaliação reflexiva", na qual os estudantes exercem "competência comunicativa", assim participando na construção das racionalidades que sustentam as práticas de avaliação.

\section{Considerações finais}

Entre os participantes da pesquisa estavam professores com distintos graus de experiência e conhecimento relativos às ferramentas de educação digital. Essa familiaridade se refletiu tanto na flexibilidade, quanto na segurança relativas às modificações introduzidas em suas práticas de avaliação durante a pandemia. A análise do conteúdo das entrevistas apontou que, no período de ensino remoto em decorrência da suspensão provisória das aulas presenciais devido ao impacto da COVID-19, eles efetuaram alguma mudança em suas práticas de avaliação - ainda que mantendo formas similares ou pouco distantes daquelas às quais os estudantes estavam acostumados. Houve também uma ressignificação do papel da avaliação. A análise também revelou algumas preocupações compartilhadas entre eles, tais como relativas à incerteza sobre a adequação, alcance e consequências da avaliação da aprendizagem praticada em meio à pandemia. A urgência da transição para o ensino remoto impôs aos professores algumas adaptações, ou mesmo algum certo grau de improvisação e provisoriedade em suas práticas. Esse contexto de "pedagogia da pandemia", no entanto, possivelmente terá consequências, a serem analisadas no futuro.

O Parecer do CNE (BRASIL, 2020) sugere que, após a pandemia, quando houver restabelecimento do ensino presencial, as instituições realizem uma "avaliação institucional diagnóstica da situação do aprendizado nos cursos e individualmente, para além das avaliações de desempenho já realizadas, de forma a construir cenários de políticas de aprendizado 
adequadas ao retorno à presencialidade". Tal como observou uma professora entrevistada, “mais adiante será necessária uma avaliação da avaliação”. Assim, apóso inesperado, a reflexão necessária. E o que essa leitura futura vai nos mostrar? É provável que reitere o estado de fragilidade da educação superior brasileira, há muito sinalizado por Marilena Chaú, que nos ensinou o quanto a formação nas universidades brasileiras parece estar a serviço da desmobilização e fragmentação do conhecimento, quando deveria formar e criar pensamento (CHAUÍ, 1994).

Nos próximos anos, as análises sobre o intenso diálogo entre educação e tecnologia, desencadeado no período da pandemia, poderão nos revelar aspectos hoje ainda invisíveis sobre o pensamento e as práticas docentes. Tal como nos lembra Michel Maffesoli, o desenvolvimento tecnológico transforma o modo como os professores apresentam o mundo aos estudantes. Esta apresentação está no centro do novo desafio que nos lança a vida cotidiana em relação ao mundo, com suas muitas experiências a serem investigadas. Além disso, as tecnologias modernas são o elemento principal do reencantamento pelo mundo, que é o desafio mais importante colocado às universidades, sendo o trabalho dos professores (MAFESSOLI, 2012, 2014). Em meio a tantas pressões, talvez o maior desafio tenha sido realmente o de manter vivo o olhar de encantamento pelo mundo.

\section{Referências}

BRASIL. Parecer CNE/CP 5/2020. Reorganização do Calendário Escolar e da possibilidade de cômputo de atividades não presenciais para fins de cumprimento da carga horária mínima anual, em razão da Pandemia da COVID-19. Brasília: CNE, 2020.

BRASIL. Censo da educação superior. Brasília: INEP, 2019.

BRISCOE, G., SADEDIN, S.; DE WILDE, P. Digital ecosystems: ecosystem-oriented architectures. Natural Computing, Basel, v. 10, n. 3, p. 1143-1194, 2011.

CHAUI, M. Escritos sobre a universidade. São Paulo: EDUNESP, 2001.

CARDOZIER, V. R. Colleges and universities in World War II. Westport: Praeger, 1993.

CRODA, J. et al. COVID-19 in Brazil: advantages of a socialized unified health system and preparation to contain cases. Revista da Sociedade Brasileira de Medicina Tropical, Brasília, v. 53, p. 1-6, 2020.

DARIAN-SMITH, K.; WAGHORNE, J. The First World War, the universities and the professions in Australia 1914-1939. Melbourne: MUP, 2019. 
DIAS SOBRINHO, J. Avaliação educativa: produção de sentidos com valor de formação. Avaliação, v. 13, n. 1, p. 193-207, 2008.

EISNER, E. The enlightened eye: qualitative inquiry and the enhancement of educational practice. New York: Teachers College Press, 2017.

HADJI, C. Avaliação desmistificada. Porto Alegre: Artmed, 2001.

HADJI, C. Avaliação, as regras do jogo: das intenções aos instrumentos. Porto: Porto, 1997.

HADJI, C. L'évaluation des actions éducatives. Paris : PUF, 1992.

HODGES, C. et al. The difference between emergency remote teaching and online learning. EDUCAUSE Review, Louisville, v. 55, n. 2, p. 1-8, March 2020.

KERR, C. Higher education cannot escape history. New Directions for Higher Education, San Francisco, v. 70, p. 5-17, 1990.

LAANPERE, M. et al. Pedagogy-driven design of digital learning ecosystems. Computer Science and Information Systems, Novi Sad, v. 11, n. 1, p. 419-442, 2012.

LINCOLN, R. College adopts grading policy changes for spring term. The Harvard Gazette, Cambridge, March 2020. Disponível em: https://news.harvard.edu/gazette/story/2020/3/. Acesso em: 10 abr. 2020.

LUCKESI, C. C. Avaliação da aprendizagem escolar: estudos e proposições. 22. ed. São Paulo: Cortez, 2011.

LUZ, A. A. A avaliação no ensino superior. Educar em Revista, Curitiba, v. 13, p. 55-66, 1997.

MAFFESOLI, M. Net-activisme: du mythe traditionnel à la cyberculture postmoderne. Sociétés, Paris, v. 124, n. 2, p. 7-19, 2014.

MAFFESOLI, M. O futuro da universidade. São Paulo: USP, 2012. Palestra. Disponível em: http://iptv.usp.br/portal/video.action?Iditem=10288. Acesso em: 10.mar.2020.

MEANS, B.; BAKIA, M.; MURPHY, R. Learning online: what research tells us about whether, when and how. New York: Routledge, 2014.

MEIRIEU, P. Postuler la compétence. In: UBALDI, J-L. (ed.). Les compétences. Paris: Editions Revue EPS, 2005. P. 11-26.

MEIRIEU, P. A pedagogia entre o dizer e o fazer. Porto Alegre: Artmed, 2002.

MESSICK, S. Meaning and values in test validation: the science and ethics of assessment. Educational Researcher, v. 18, n. 2, p. 5-11, 1989.

MEZIROW, J. Transformative dimensions of adult learning. San Francisco: Jossey-Bass, 1991. 
PATTON, M. Q. Qualitative evaluation and research methods. 2. ed. Newbury Park: Sage, 1991.

ROESE, N.; SHERMAN, J. Expectancy. In: KRUGLANSKI, A.; HIGGINS, E. (ed.). Social psychology: handbook of basic principles. 2. ed. New York: Guilford Press, 1997. p. 91-115.

ROMÃO, J. E. Avaliação dialógica: desafios e perspectivas. 6. ed. São Paulo: Cortez, 2005.

RUDY, W. Total war and twentieth-century higher learning: universities of the western world in the First and Second World Wars. Rutherford: Fairleigh Dickinson University Press, 1991.

TITTLE, C.; HECHT, D.; MOORE, P. Assessment theory and research for classrooms: from taxonomies to constructing meaning in context. Educational Measurement: Issues and Practice, Mount Royal, v, 12, n. 4, p. 13-19, 2005.

TAYLOR, J. The impact of the First World War on British Universities. London: Palgrave Macmillan, 2018.

UNESCO. COVID-19 impact on education. Montreal: UNESCO Institute for Statistics, 2020. 